\title{
Multistep photoinduced electron transfer in self-organised nanoscale porphyrin triads
}

\author{
Eduard I. Zenkevich ${ }^{\mathrm{a}, *}$, Alexander M. Shulga ${ }^{\mathrm{a}}$, Christian von Borczyskowski $^{\mathrm{b}}$

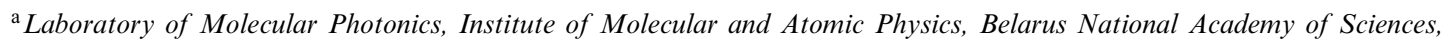 \\ F. Skaryna Avenue 70, 220072, Minsk, Belarus \\ ${ }^{\mathrm{b}}$ University of Technology Chemnitz, Reichenhainer Str. 70, 09107 Chemnitz, Germany
}

\begin{abstract}
Well-defined structurally organised porphyrin triads of a controlled geometry and nanoscale size have been formed in liquid solutions using the combination of a covalent approach and non-covalent self-assembly. The triads contain zinc-octaethylporphyrin chemical dimer, $(\mathrm{ZnOEP})_{2} \mathrm{Ph}$, with covalently linked electron acceptors (p-benzoquinone, $\mathrm{Q}$ or pyromellitimide, Pim), and additional dipyridyl-substituted tetrapyrrole extra-ligands. Steady-state, picosecond fluorescence $\left(\Delta t_{1 / 2} \approx 75 \mathrm{ps}\right)$ and femtosecond pump-probe $\left(\Delta_{1 / 2} \approx 280 \mathrm{fs}\right)$ data show that non-radiative deactivation of the dimer $\mathrm{S}_{1}$-states $\left(\tau_{\mathrm{S}}<1 \mathrm{ps}\right)$ is due to both the $\mathrm{S}-\mathrm{S}$ energy transfer $(\mathrm{ZnOEP})_{2} \mathrm{Ph} \rightarrow$ extra-ligand and the sequential photoinduced electron transfer $(\mathrm{ZnOEP})_{2} \mathrm{Ph} \rightarrow \mathrm{Q}$ (or Pim) at $r_{\mathrm{DA}}=10.8 \AA$. The additional decay shortening of the extra-ligand $\mathrm{S}_{1}$-states by 3-6 times (toluene, $293 \mathrm{~K}$ ) is attributed to the increased "superexchange" mediated long distant ( $r_{\mathrm{DA}} \approx 18-21 \AA$ ) one-step electron transfer extra-ligand $\rightarrow$ Q (or Pim). (c) 2002 Elsevier Science B.V. All rights reserved.
\end{abstract}

Keywords: Nanosized porphyrin triads; Fluorescence quenching; Time-resolved spectroscopy; Charge and energy transfer

\section{Introduction}

Porphyrins and chlorophylls play a key role in the primary photoevents in photosynthesis involving the cascade of photoinduced electron-transfer (ET) steps realised in natural nanoscale structures $[1,2]$. The preparation of model multimolecular assemblies with functional properties to mimic important features of ET in vivo or to gain some insight into the principal possibilities of nanoelectronics and photovoltaics is one of the most popular tendencies of supramolecular photochemistry $[3,4]$. A great number of well-defined multiporphyrin arrays have been studied for a better

\footnotetext{
* Corresponding author. Tel.: +375-172-841-563; fax: +375172-840-030.

E-mail address: zenkev@imaph.bas-net.by (E.I. Zenkevich).
}

understanding of the factors and mechanisms which control the efficiency and directionality of the energy and ET reactions [5,6, and references therein]. Apart from covalent linking the desired subunits the non-covalent self-assembly of various kinds has attracted a lot of interest [7]. In this relation, using the complexation of Zn-porphyrin chemical dimers by pyridyl-substituted tetrapyrrole extra-ligands (via two-point extra-coordination) we have succeeded to form self-organised nanosized multimolecular tetrapyrrole assemblies in solutions and films $[8,9]$.

Here, we discuss the dynamics of relaxation processes in self-assembled triads composed of Zn-octaethylporphyrin chemical dimer, $(\mathrm{ZnOEP})_{2} \mathrm{Ph}$, with covalently linked electron acceptor $A$ (parabenzoquinone, Q, or pyromellitimide, Pim), and self-assembled tetrapyrrole extra-ligand (porphyrin, $\mathrm{P}$, 

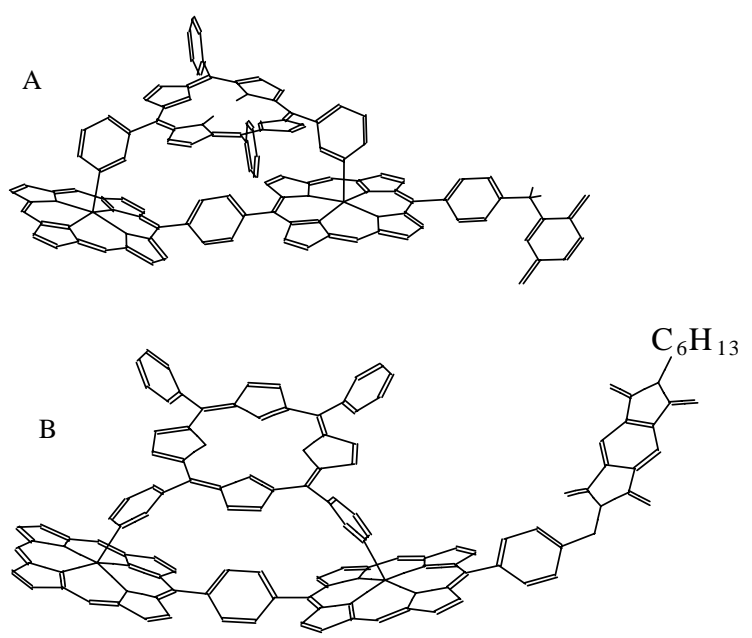

Fig. 1. Optimised structures of the triads with electron acceptors $\mathrm{Q}$ and Pim (HyperChem, release 4, semiempirical method PM3): (A) triad $(\mathrm{ZnOEP})_{2} \mathrm{Ph}-\mathrm{Q} \otimes \mathrm{H}_{2} \mathrm{P}(\mathrm{m}-\mathrm{Pyr})_{2}$-(iso- $\left.\mathrm{PrPh}\right)_{2}$ containing porphyrin extra-ligand with opposite pyridyls; (B) triad $(\mathrm{ZnOEP})_{2} \mathrm{Ph}-\mathrm{Pim} \otimes \mathrm{H}_{2} \mathrm{P}\left(\mathrm{m}^{\wedge} \mathrm{Pyr}\right)_{2}$-(iso- $\left.\mathrm{PrPh}\right)_{2}$ containing porphyrin extra-ligand with adjacent pyridyls.

chlorin, Chl, or tetrahydroporphyrin, THP) (Fig. 1). Fluorescence decay was measured by time-correlated single photon counting (TCSPC) technique (exciting dye laser Spectra $\mathrm{Ar}^{+}$-Laser Mod. 171/Dye-Laser Mod. 343, a repetition-rate of $4 \mathrm{MHz}$, pulses of $15 \mathrm{ps}$ FWHM, detection under the magic angle of $54.7^{\circ}$, the system response $\Delta t_{1 / 2}=75 \mathrm{ps}$, the convolution with three times for each data set using global analysis fit). Pump-probe experiments involved a Coherent MIRA 900 Ti:sapphire laser with a regenerative amplifier and a parametric oscillator running at $1 \mathrm{kHz}$ (excitation in the $400-800 \mathrm{~nm}$ range, $\Delta_{1 / 2} \approx 280 \mathrm{fs}$ ).

\section{Results and discussion}

Steady-state absorption spectra of the triads are essentially a linear combination of the dipyridinated dimer $(\mathrm{ZnOEP})_{2} \mathrm{Ph}$, extra-ligand and $A[8,9]$. Thus, the interaction between the corresponding subunits is weak in the ground state, and they retain their individual identities. Fluorescence spectra of $A$-containing triads consist of the extra-ligand fluorescence bands and are characterised by the substantial quenching of the dimer $(\mathrm{ZnOEP})_{2} \mathrm{Ph}$ emission [9]. It means that the initial fluorescence of the $A$-containing dimers
$(\mathrm{ZnOEP})_{2} \mathrm{Ph}-\mathrm{Q}$ or $(\mathrm{ZnOEP})_{2} \mathrm{Ph}-\mathrm{Pim}$ being strongly quenched due to ET process dimer $\rightarrow A[9,10]$, does show a remarkable additional quenching upon the triad formation (toluene, $293 \mathrm{~K}$ ). The second feature of the $A$-containing triads is that the fluorescence quantum efficiency of complexed extra-ligands is smaller essentially with respect to that found for the same extra-ligands in the triads without $A$ 's.

TCSPC measurements (Table 1) get a more quantitative insight into the dynamics of relaxation processes in the systems under consideration. It is worth noting that a small but noticeable shortening of fluorescence decays was detected for the same extra-ligands in triads without $A$ 's that was attributed to a photoinduced hole transfer from the extra-ligand to the dimer [11]. Experimental data collected in the Table show also that for the triads of the same geometry but having extra-ligands of various nature the extra-ligand fluorescence decay shortening decreases in the following sequence: $\mathrm{H}_{2} \mathrm{P}(\mathrm{m}-\mathrm{Pyr})_{2}$-(iso $\left.\rightarrow \mathrm{PrPh}\right)_{2} \rightarrow$ $\mathrm{H}_{2} \mathrm{Chl}(\mathrm{m}-\mathrm{Pyr})_{2} \rightarrow \mathrm{H}_{2} \mathrm{THP}(\mathrm{m}-\mathrm{Pyr})_{2}$. In fact, TCSPC data reflect the final steps of the electronic energy excitation dynamics in $A$-containing triads. Really, femtosecond pump-probe results reveal the faster complex non-radiative excited state behaviour being observed within $\tau_{1}=0.7-7.0 \mathrm{ps}$ for the triads $(\mathrm{ZnOEP})_{2} \mathrm{Ph}-\mathrm{Q} \otimes \mathrm{H}_{2} \mathrm{P}(\mathrm{m}-\mathrm{Pyr})_{2}$-(iso- $\left.\mathrm{PrPh}\right)_{2}$ and $(\mathrm{ZnOEP})_{2} \mathrm{Ph}-\mathrm{Pim} \otimes \mathrm{H}_{2} \mathrm{P}\left(\mathrm{m}^{\wedge} \mathrm{Pyr}\right)_{2}$-(iso- $\left.\mathrm{PrPh}\right)_{2}$ in toluene at $293 \mathrm{~K}$ (Fig. 2). The detailed analysis of femtosecond spectral-kinetic data (presented in our forthcoming papers $[11,12]$ ) shows that the formation of charge transfer (CT) states could be appropriately detected, and the primary fast deactivation of the locally excited $\mathrm{S}_{1}$-states of interacting subunits (the dimer and extra-ligand) is caused by the competition between the energy migration and sequential electron/hole transfer.

Using schematic energy level diagram for Acontaining triads (Fig. 3) based on the obtained experimental data one may discuss possible pathways, which are responsible, for the observed shortening of the dimer and the extra-ligand locally excited $\mathrm{S}_{1}$-states. Once directly excited, $\mathrm{S}_{1}$-state (Lig... ${ }^{1}$ Dimer...A) of the dimer $(\mathrm{ZnOEP})_{2} \mathrm{Ph}$ may be deactivated due to the following non-radiative processes: (i) one-step ET $\left(\right.$ Lig... ${ }^{1}$ Dimer* $\left.^{*} . . \mathrm{A}\right) \stackrel{k_{9}}{\rightarrow}\left(\right.$ Lig....Dimer $\left.^{+} \ldots \mathrm{A}^{-}\right), k_{9}=$ $0.66 \times 10^{10} \mathrm{~s}^{-1}$ for Pim and $k_{9}=2.86 \times 10^{10} \mathrm{~s}^{-1}$ for Q (our own data for the dimers $(\mathrm{ZnOEP})_{2} \mathrm{Ph}-A$ without 
Table 1

Structural, kinetic and redox parameters for superexchange ET in triads with electron acceptors (toluene, $293 \mathrm{~K}$ )

\begin{tabular}{|c|c|c|c|c|c|c|c|c|c|c|}
\hline \multicolumn{3}{|l|}{ Triad Components: } & \multirow{2}{*}{$\begin{array}{l}E\left(\mathrm{~S}_{1}^{\mathrm{D}}\right)^{\mathrm{a}} \\
(\mathrm{eV})\end{array}$} & \multirow{2}{*}{$\begin{array}{l}r_{\mathrm{DB}}^{\mathrm{b}} \\
(\AA)\end{array}$} & \multirow{2}{*}{$\begin{array}{l}r_{\mathrm{DA}}{ }^{\mathrm{b}} \\
(\AA)\end{array}$} & \multirow{2}{*}{$\begin{array}{l}E_{\mathrm{D}}^{\mathrm{oxc}} \\
(\mathrm{eV})\end{array}$} & \multirow{2}{*}{$\begin{array}{l}E_{\mathrm{D}^{+} \mathrm{B}^{-} \mathrm{A}^{\mathrm{d}}} \\
(\mathrm{eV})\end{array}$} & \multirow{2}{*}{$\begin{array}{l}\tau_{\mathrm{S} 0}^{\mathrm{D}} \\
(\mathrm{ns})\end{array}$} & \multirow{2}{*}{$\begin{array}{l}\tau_{\mathrm{S}}^{\mathrm{De}} \\
(\mathrm{ns})\end{array}$} & \multirow{2}{*}{$\begin{array}{l}k_{\mathrm{ET}} / 10^{8 \mathrm{f}} \\
\left(\mathrm{s}^{-1}\right)\end{array}$} \\
\hline Donor & Bridge & Acceptor & & & & & & & & \\
\hline $\mathrm{H}_{2} \mathrm{P}(\mathrm{m}-\mathrm{Pyr})_{2}-(\text { iso- } \mathrm{PrPh})_{2}$ & $(\mathrm{ZnOEP})_{2} \mathrm{Ph}$ & Q & 1.91 & 8.2 & 18.0 & 1.10 & 3.08 & 6.2 & 0.94 & 9.0 \\
\hline $\mathrm{H}_{2} \mathrm{Chl}(\mathrm{m}-\mathrm{Pyr})_{2}$ & $(\mathrm{ZnOEP})_{2} \mathrm{Ph}$ & Q & 1.89 & 8.2 & 18.0 & 1.07 & 3.05 & 6.6 & 1.24 & 6.5 \\
\hline $\mathrm{H}_{2} \mathrm{THP}(\mathrm{m}-\mathrm{Pyr})_{2}$ & $(\mathrm{ZnOEP})_{2} \mathrm{Ph}$ & Q & 1.66 & 8.2 & 18.0 & 1.09 & 3.07 & 4.3 & 1.04 & 7.3 \\
\hline $\mathrm{H}_{2} \mathrm{P}\left(\mathrm{m}^{\wedge} \mathrm{Pyr}\right)_{2}-(\text { iso- } \mathrm{PrPh})_{2}$ & $(\mathrm{ZnOEP})_{2} \mathrm{Ph}$ & Q & 1.91 & 9.1 & 20.8 & 1.10 & 3.08 & 7.7 & 0.95 & 9.2 \\
\hline $\mathrm{H}_{2} \mathrm{P}\left(\mathrm{m}^{\wedge} \mathrm{Pyr}\right)_{2}$-(iso- $\left.\mathrm{PrPh}\right)_{2}$ & $(\mathrm{ZnOEP})_{2} \mathrm{Ph}$ & Pim & 1.91 & 9.1 & 24.2 & 1.10 & 3.08 & 7.7 & 2.67 & 2.5 \\
\hline
\end{tabular}

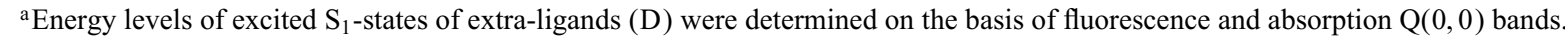

${ }^{\mathrm{b}}$ Intercenter distances $r_{\mathrm{DB}}, r_{\mathrm{DA}}$ and molecular radii $r_{\mathrm{D}}=r_{\mathrm{B}} 5.5 \AA, r_{\mathrm{A}}=3.5 \AA(\mathrm{Pim})$ or $3.3 \AA(\mathrm{Q})$ were estimated from optimised structures of the triads (Fig. 1).

${ }^{\mathrm{c}}$ Redox potentials for the subunits were extracted from the literature data: oxidation potentials $E_{\mathrm{D}}^{\mathrm{ox}}$ for extra-ligands $\mathrm{H}_{2} \mathrm{P}(\mathrm{m}-\mathrm{Pyr})_{2}, \mathrm{H}_{2} \mathrm{Chl}(\mathrm{m}-\mathrm{Pyr})_{2}, \mathrm{H}_{2} \mathrm{THP}(\mathrm{m}-\mathrm{Pyr})_{2}$ (in DMF vs. SCE) from Refs. [13-16]; the reduction potential for coordinated dimer $(\mathrm{ZnOEP})_{2} \mathrm{Ph} E_{\mathrm{B}}^{\text {red }}=-1.69 \mathrm{~V}$ (in DMSO vs. SCE, [13]); one electron reduction potentials (DMF, vs. SCE) were taken for Pim $E_{1 / 2}^{\text {red }}=-0.76 \mathrm{~V}[10]$ and for $\mathrm{Q} E_{1 / 2}^{\mathrm{red}}=-0.45 \mathrm{~V}[17]$.

${ }^{\mathrm{d}}$ The energy $E_{\mathrm{D}^{+} \mathrm{B}^{-} \mathrm{A}}$ of a bridge level was estimated by [5,9-11]

$E_{\mathrm{D}^{+} \mathrm{B}^{-} \mathrm{A}}=e\left(E_{\mathrm{D}}^{\mathrm{ox}}-E_{\mathrm{A}}^{\mathrm{red}}\right)+\Delta G_{\mathrm{S}}, \Delta G_{\mathrm{S}}=\frac{e^{2}}{4 \pi \varepsilon_{0}}\left[\left(\frac{1}{2 r_{\mathrm{D}}}+\frac{1}{2 r_{\mathrm{A}}}-\frac{1}{r_{\mathrm{DA}}}\right) \frac{1}{\varepsilon}-\left(\frac{1}{2 r_{\mathrm{D}}} \frac{1}{\varepsilon_{\mathrm{D}}^{\prime}}+\frac{1}{2 r_{\mathrm{A}}} \frac{1}{\varepsilon_{\mathrm{A}}^{\prime}}\right)\right]$

with dielectric constants of $\varepsilon($ toluene $)=2.38$ and $\varepsilon_{\mathrm{A}}^{\prime}=\varepsilon_{\mathrm{D}}^{\prime}=36.7(\mathrm{DMF})$.

${ }^{\mathrm{e}} \tau_{\mathrm{S} 0}^{\mathrm{D}}$ and $\tau_{\mathrm{S}}^{\mathrm{D}}$ values correspond to fluorescence decays for extra-ligands in triads without and with additional $A$ 's, respectively.

${ }^{\mathrm{f}}$ photoinduced electron transfer rate constants $k_{\mathrm{ET}}$ were calculated by $k_{\mathrm{ET}}=\left(\tau_{\mathrm{S}}^{\mathrm{D}}\right)^{-1}-\left(\tau_{\mathrm{S} 0}^{\mathrm{D}}\right)^{-1}$.

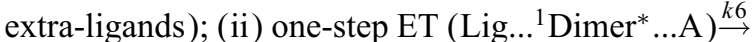
$\left(\mathrm{Lig}^{-} \ldots \mathrm{Dimer}^{+}\right.$...A); (iii) non-radiative singletsinglet energy transfer, $\left(\right.$ Lig... ${ }^{1}$ Dimer $\left.^{*} . . . \mathrm{A}\right) \stackrel{k_{5}}{\rightarrow}\left({ }^{1} \mathrm{Lig}^{*}\right.$.. Dimer...A).

According to our recent results [11] $\left(k_{5}+k_{6}\right)=$ $1 / 1.7 \mathrm{ps}=5.9 \times 10^{11} \mathrm{~s}^{-1}$. Thus, $\left(k_{5}+k_{6}\right) \gg k_{9}$, and the direct one-step ET process (i) is low probable with respect to processes (ii) and (iii). In addition, $\left(k_{5}+k_{6}\right) \gg k_{1}=1 / \tau_{\mathrm{S}}^{0}=1 / 1.15 \mathrm{~ns}=8.7 \times 10^{8} \mathrm{~s}^{-1}$, thus no detectable fluorescence of the dimer $(\mathrm{ZnOEP})_{2} \mathrm{Ph}$ is observed in the triads. The solvent polarity increase leads to a full disappearance of sensitised fluorescence of the extra-ligand in the triads, thus the sequential ET (ii) becomes dominant in the non-radiative deactivation of the dimer $S_{1}$-state with respect to the process (iii).

It follows from the scheme in Fig. 3 that at $293 \mathrm{~K}$ the extra-ligand $\mathrm{S}_{1}$-state $\left({ }^{1}\right.$ Lig $^{*}$....Dimer...A) could arise from both direct photoexcitation and fast $(<10 \mathrm{ps}$ [11]) exothermic energy transfer $\left(\right.$ Lig... ${ }^{1}$ Dimer...A $) \rightarrow\left({ }^{1}\right.$ Lig* $^{*} .$. Dimer...A $)$ or via thermally activated charge recombination $\left(\mathrm{Lig}^{-}\right.$...Dimer ${ }^{+}$ ...A $\stackrel{k_{8}}{\rightarrow}\left(\right.$ Dimer... ${ }^{1}$ Lig $^{*}$...A $)$. Once formed, the excited
$\mathrm{S}_{1}$-state of the extra-ligand may decay via two non-radiative processes:

(iv) bridge-mediated long-distance superexchange ET, discussed in Refs. [9,10,18,19] ( ${ }^{1} \mathrm{Lig}^{*}$...Dimer $\ldots \mathrm{A}) \stackrel{k_{\text {superexchange }}}{\longrightarrow}\left(\mathrm{Lig}^{+}\right.$...Dimer.... $\left.\mathrm{A}^{-}\right)$, where $(\mathrm{ZnOEP})_{2} \mathrm{Ph}$ dimer is a bridge;

(v) photoinduced hole transfer $\left({ }^{1}\right.$ Lig $^{*}$...Dimer...A) $\stackrel{k_{7}}{\longrightarrow}\left(\mathrm{Lig}^{-} \ldots\right.$ Dimer $^{+}$...A $)$.

Superexchange ET occurs because of coherent mixing of the three or more states of the system $[18,19]$ (these states are shown as $\left|\mathrm{D}^{*} \mathrm{BA}\right\rangle,\left|\mathrm{D}^{+} \mathrm{B}^{-} \mathrm{A}\right\rangle$ and $\left|\mathrm{D}^{+} \mathrm{BA}^{-}\right\rangle$in Fig. 3). Being not directly populated a high-lying "spectator" state $\left|\mathrm{D}^{*} \mathrm{~B}^{-} \mathrm{A}\right\rangle$ mediates the distant ET from a donor state $\left|\mathrm{D}^{*} \mathrm{BA}\right\rangle$ to $\mathrm{CT}$ state $\left|\mathrm{D}^{+} \mathrm{BA}^{-}\right\rangle$. Within this model the charge separation rate constant $k_{\text {super }} \sim\left(\mathrm{V}_{12} \cdot \mathrm{V}_{23} / \delta \mathrm{E}\right) . \mathrm{V}_{12}$ and $\mathrm{V}_{23}$ are the electronic coupling terms for ET processes $\left|\mathrm{D}^{*} \mathrm{BA}\right\rangle \rightarrow\left|\mathrm{D}^{+} \mathrm{B}^{-} \mathrm{A}\right\rangle$ and $\left|\mathrm{D}^{+} \mathrm{B}^{-} \mathrm{A}\right\rangle \rightarrow\left|\mathrm{D}^{+} \mathrm{BA}^{-}\right\rangle$, respectively, both being essentially lower than the energy differences between the relevant system states. $\delta \mathrm{E}$ is the energy difference of $\left|\mathrm{D}^{+} \mathrm{B}^{-} \mathrm{A}\right\rangle$ and the crossing point of the potential energy curves of $\left|D^{*} B A\right\rangle$ 


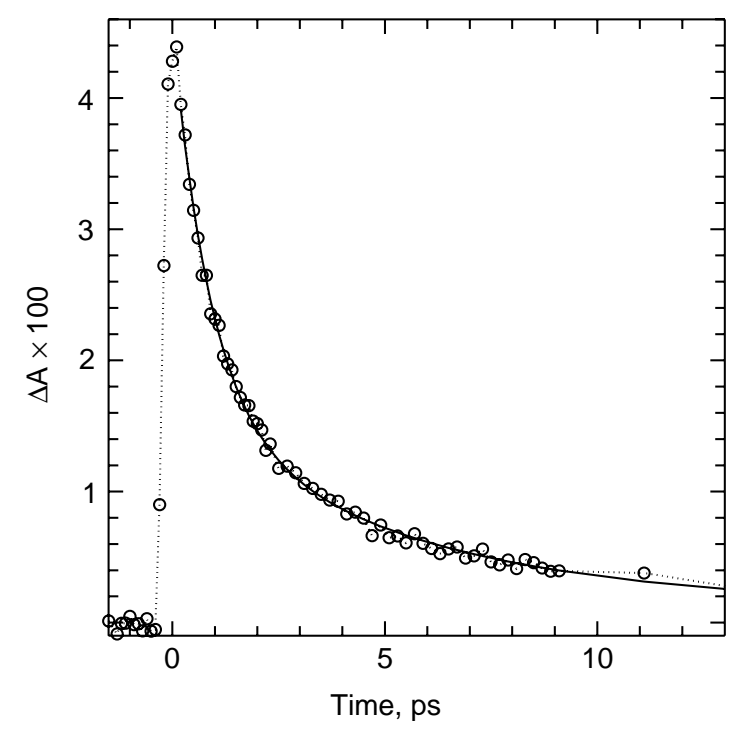

Fig. 2. Time evolution of the transient absorbance for the triad $(\mathrm{ZnOEP})_{2} \mathrm{Ph}-\mathrm{Pim} \otimes \mathrm{H}_{2} \mathrm{P}\left(\mathrm{m}^{\wedge} \mathrm{Pyr}\right)_{2}$-(iso- $\left.\mathrm{PrPh}\right)_{2}$ in toluene at $293 \mathrm{~K}$ formed by the excitation at $\lambda_{\text {pump }}=555 \mathrm{~nm}$ (in the dimer absorption band) and detected at $515 \mathrm{~nm}$ (the region of the extra-ligand ground state bleaching cased by the formation of $\mathrm{H}_{2} \mathrm{P}^{*}$ and $\mathrm{H}_{2} \mathrm{P}^{-}$species). Two-exponential fit $I(t)=A_{1} \exp (-t)+A_{2} \exp \left(-t / \tau_{2}\right)+\delta(t)$ gives $\tau_{1}=0.9 \mathrm{ps}$ $\left(A_{1}=0.029\right)$ and $\tau_{2}=5.4 \mathrm{ps}\left(A_{2}=0.015\right)$.

and $\left|\mathrm{D}^{+} \mathrm{BA}^{-}\right\rangle$along the reaction co-ordinate. As is seen from Table 1 superexchange ET rate constants are hardly dependent on the extra-ligand nature and the triad organisation (because of a strong electronic coupling term $\mathrm{V}_{12}$ ). At the same time the decrease in ET rate constant for Pim-containing triad with respect to that for the triad with Q (by more than 3 times, Table) may be due to the increase of $r_{D B}$ and $r_{D A}$ distances as well as changes of the energy of $\left|D^{+} B^{+} A\right\rangle$ and $\left|\mathrm{D}^{+} \mathrm{BA}^{-}\right\rangle$states.

At last, it should be mentioned that hole transfer pathway (v) leads to the formation of CT state $\left(\mathrm{Lig}^{-}\right.$...Dimer $\left.{ }^{+}\right)$which is not a final CT state in $A$-containing triads. Indeed, both ET processes to low-lying CT states, $\left(\mathrm{Lig}^{-} \ldots \mathrm{Dimer}^{+} \ldots \mathrm{A}\right) \rightarrow(\operatorname{Lig} \ldots$ $\left.\operatorname{Dimer}^{+} \ldots \mathrm{A}^{-}\right)$and $\left(\mathrm{Lig}^{-} \ldots \mathrm{Dimer}^{+} \ldots \mathrm{A}\right) \rightarrow\left(\mathrm{Lig}^{+} \ldots\right.$ Dimer... $\mathrm{A}^{-}$), may be considered as superexchange ET processes mediated by coherent mixing of the corresponding upper lying $\mathrm{CT}$ states. The first process $\left(\mathrm{Lig}^{-} \ldots \mathrm{Dimer}^{+} \ldots \mathrm{A}\right) \rightarrow\left(\mathrm{Lig} . . . \mathrm{Dimer}^{+} \ldots \mathrm{A}^{-}\right)$is oneelectron transfer, while the second $\left(\mathrm{Lig}^{-}\right.$...Dimer ${ }^{+}$ $\ldots \mathrm{A}) \rightarrow\left(\mathrm{Lig}^{+}\right.$...Dimer.... $\left.\mathrm{A}^{-}\right)$seems to be a two-electron transfer reaction theoretically discussed in Ref. [20].

\section{Conclusions}

Self-organised nanoscale porphyrin triads containing additional electron acceptors show complex energy and electron transfer dynamics depending on the

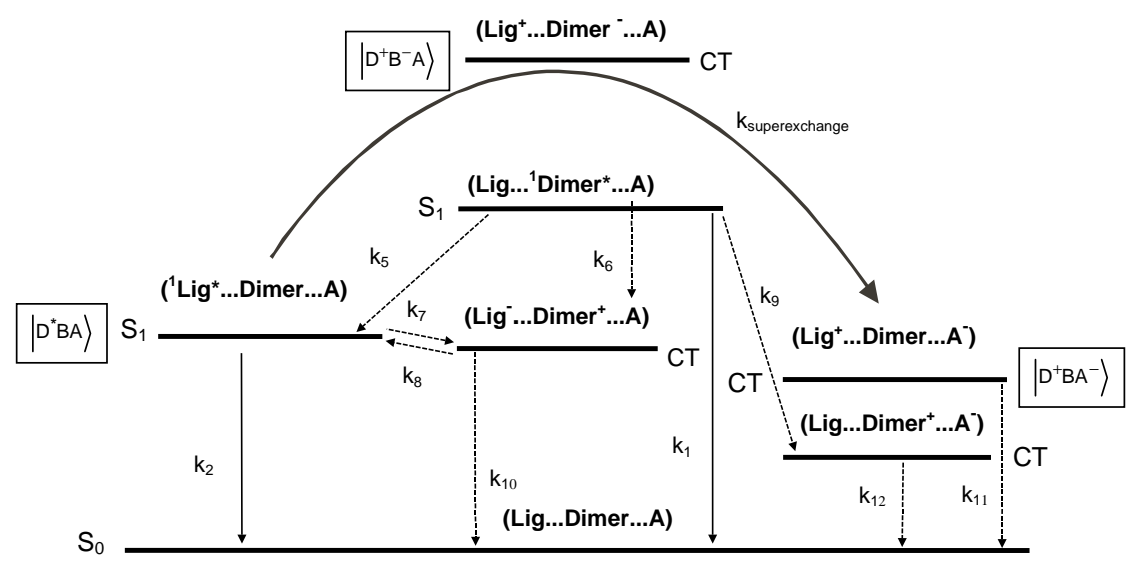

Fig. 3. Energy level diagram of excited states for triads with electron acceptor (toluene, $293 \mathrm{~K}$ ). Indicated are rate constants of deactivation processes discussed in the text. 
triad geometry, redox and photophysical properties of interacting subunits as well as on the solvent polarity. The non-radiative deactivation of locally excited $\mathrm{S}_{1}$-states in the triads includes multistep ET reactions of various nature (sequential ET, hole transfer and long-range superexchange ET to $A$ ) thus mimicking the primary charge separation in vivo.

\section{Acknowledgements}

Research was supported by DFG Schwerpunktprogramm (SPP 470, Schr 231) and partly by the National Foundation for Basic Research of Belarus (Grant No. $\mathrm{Ph}$ 99-104).

\section{References}

[1] M.-E. Michel-Beyerle (Ed.), The Reaction Center of Photosynthetic Bacteria. Structure and Dynamics, Springer, Berlin, Heidelberg, 1996.

[2] H. van Amerongen, R. van Grondele, J. Phys. Chem. B 105 (2001) 604.

[3] J.L. Sessler, B. Wang, S.L. Springs, C.T. Bown, in: Y. Marakami (Ed.), Comprehensive Supramolecular Chemistry, Vol. 4, Oxford, 1996, p. 311.

[4] M.C. Petty, M.R. Bryce, D. Bloor (Eds.), An Introduction to Molecular Electronics, (Edward Arnold, a division of Holder Headline PLC, London, Melbourne, Auckland, 1995).

[5] M.R. Wasielewski, Chem. Rev. 92 (1992) 435.

[6] H. Ogoshi, T. Mitzutani, T. Nayashi, Y. Kuroda, in: K.M. Kadish, K.M. Smith, R. Guilard (Eds.), The Porphyrin Handbook, Vol. 6, Academic Press, New York, 2000, p. 279.
[7] J.-M. Lehn, Frontiers, in: H.-J. Schneider, H. Durr (Eds.), Supramolecular Organic Chemistry and Photochemistry, (Verlagsgesellschaft mbH VCH, Weiheim, New York, Basel, Cambridge, 1991), pp. 1-28.

[8] A.V. Chernook, U. Rempel, Ch. von Borczyskowski, E.I. Zenkevich, A.M. Shulga, Chem. Phys. Lett. 254 (1996) 229.

[9] U. Rempel, S. Meyer, B. von Maltzan, C. von Borczyskowski, J. Luminesc. 78 (1998) 97.

[10] A. Osuka, H. Yamada, K. Maruyama, N. Mataga, T. Asahi, M. Ohkoshi, T. Okada, I. Yamazaki, Y. Nishimura, J. Am. Chem. Soc. 115 (1993) 9439.

[11] E.I. Zenkevich, A. Willert, S.M. Bachilo, U. Rempel, D.S. Kilin, A.M. Shulga, C. von Borczyskowski, Material Science and Engineering, C: 18 (2001) 99.

[12] E.I. Zenkevich, C. von Borczyskowski, A.M. Shulga, S.M.Bachilo, U.Rempel, A.Willert, Self-assembled nanoscale photomimetic models: structure and related dynamics. Chem. Phys. 275 (2001).

[13] J.-H. Fuhrhop, K.M. Kadish, D.G. Davis, J. Am. Chem. Soc. 95 (1973) 5140.

[14] R. Felton, in: D. Dolphin (Ed.), The Porphyrins, Vol. V, Academic Press, New York, 1978, p. 53.

[15] P. Worthington, P. Hambright, R. Williams, J. Inorg. Biochem. 12 (1980) 281.

[16] V.G. Majranowski, in: N.S. Enikolopyan (Ed.), Porphyrins: Spectroscopy, Photochemistry, Applications, Nauka, Moscow, 1987, pp. 127-181.

[17] S.L. Murrov, I. Carmichael, G.L. Hug, Handbook of Photochemistry, New-York-Basel, Hong Kong, Marcel Deccer, Inc. 1993, pp. 269-278.

[18] W. Davis, M.R. Wasielewski, M. Ratner, V. Mujica, A. Nitzan, J. Phys. Chem. 101 (1997) 6158.

[19] D. Kilin, U. Kleinekathofer, M. Schreiber, J. Phys. Chem. A 104 (2000) 5413.

[20] T. Bandyopadhyay, A. Okada, M. Tachiya, J. Chem. Phys. 110 (1999) 9630. 